\title{
Medical student exposure to anesthesiology through the Pre- clerkship Residency Exploration Program: impact on career interest and understanding of anesthesiology
}

\author{
Michael Smyth, BSc, MSc (D) - J. Thomas Toguri, BSc, PhD • Todd Dow, BSc • \\ Thomas Sebastian Haupt, BA · Alysha Roberts, BSc $\cdot$ Kavita Raju, BSc, MSc
}

Received: 23 January 2019/Revised: 13 May 2019/Accepted: 14 May 2019/Published online: 21 May 2019

(c) Canadian Anesthesiologists' Society 2019

\section{To the Editor,}

According to the Canadian Residency Matching Service (CaRMs), the number of medical students seeking a career in anesthesia increased from 106 students in 2008 to 151 students in 2019. ${ }^{1}$ Despite the increasing interest in anesthesiology, the number of residency positions has remained relatively unchanged, ranging between 99 and 111 spots, over the same time period.

Students begin to shape their career decisions early in medical school, often prior to clerkship. ${ }^{2}$ To assist students at Dalhousie University, we launched the inaugural Preclerkship Residency Exploration Program (PREP) in 2018. The PREP provided second-year medical students with a multi-faceted exposure to ten medical specialties, including anesthesiology. The course included participation in halfday electives, informal career discussions, specialityspecific workshops, procedural skills sessions, and simulations over a two-week period. ${ }^{3}$ We surveyed PREP attendees to determine understanding and interest in various specialties, including anesthesiology.

Following institutional ethical approval by Nova Scotia Health Authority Research Ethics Board (2018-04-11), a questionnaire was distributed to PREP participants prior to and immediately following the program. Pre-program questionnaires assessed participant demographics and understanding of the role of anesthesiology; post-program questionnaires gauged participants' change in interest in anesthesiology following the program.

\footnotetext{
M. Smyth, BSc, MSc $(\bowtie) \cdot J$ J. T. Toguri, BSc, PhD

T. Dow, BSc · T. S. Haupt, BA · A. Roberts, BSc .

K. Raju, BSc, MSc

Dalhousie Medical School, Dalhousie University, Halifax, NS,

Canada

e-mail: m.smyth@dal.ca
}

Following PREP, when participants were asked "Do you understand the daily responsibilities of an anesthesiologist?", the proportion of participants who "agreed" or "strongly agreed" to the statement, on a five-point Likert scale $(1=$ strongly disagree, $5=$ strongly agree), increased from 12 of 36 (33.3\%) pre-PREP to 24 of 37 (64.9\%) post-PREP (Table). In addition, mean scores increased from 3.0 pre-program to 3.6 post-program on the same five-point Likert scale. Following PREP, 18 of 37 participants $(48.7 \%)$ said that their interest in anesthesiology increased. To help clarify what aspects of the program were responsible for participants' change in interest in the speciality, they were asked to select which aspect of the program was most responsible for their change in interest. The anesthesiology elective portion of the program (8 of $37 ; 21.6 \%$ ) and skills sessions (5 of 37; $13.5 \%$ ) were cited as major reasons for participants' increased interest in anesthesiology (Table). Participants were also asked to rate their comfort with various skills often performed by anesthesiologists on a five-point Likert scale. We observed a significant increase in participant comfort with each skill practiced: intubation $(P \leq 0.001)$, intravenous catheter insertion $(P \leq 0.001)$, central venous catheter insertion $(P \leq 0.001)$, and intraosseous access $(P=$ 0.007, Table).

Currently, five of the 17 Canadian medical schools (including Dalhousie University) lack mandatory anesthesiology rotations. Furthermore, it has been shown that in six of the 17 medical schools, less than $1 \%$ of the pre-clerkship teaching hours are taught by anesthesiology faculty members in Canada. ${ }^{4}$ Work done by Henschke et al. at the University of Alberta ( $\mathrm{U}$ of $\mathrm{A})$ has shown students' desire to have anesthesiology as part of their curriculum, having found that $80 \%$ of third-year and $92 \%$ of fourth-year medical students at $\mathrm{U}$ of $\mathrm{A}$ believe that 
Table PREP participant survey

Understanding of anesthesiology

\begin{tabular}{llllll}
\hline & Strongly disagree & Disagree & Neutral & Agree & Strongly agree \\
\hline Pre-PREP & 1 & 14 & 19 & 8 & 4 \\
Post-PREP & 0 & 3 & 10 & 24 & 0 \\
\hline
\end{tabular}

Program aspects responsible for change in interest in anesthesiology

\begin{tabular}{llll}
\hline & $\begin{array}{l}\text { Decreased interest in } \\
\text { anesthesiology }\end{array}$ & $\begin{array}{l}\text { Interest in anesthesiology } \\
\text { remained the same }\end{array}$ & $\begin{array}{l}\text { Increased interest in } \\
\text { anesthesiology }\end{array}$ \\
\hline Anesthesiology elective & 5 & 2 & 8 \\
Skills sessions & 0 & 3 & 5 \\
Anesthesiology workshop & 0 & 1 & 1 \\
Resident lifestyles talk & 0 & 0 & 1 \\
Other & 0 & 8 & 3 \\
\hline
\end{tabular}

Skills assessments

\begin{tabular}{|c|c|c|c|c|}
\hline Skill performed & $n$ & Mean $(95 \% \mathrm{CI})$ & Mean difference & $P$ value \\
\hline \multicolumn{5}{|l|}{ Intubation } \\
\hline Previously performed & $27(81.8 \%)$ & & & \\
\hline Pre-session comfort & 33 & $2.4(2.0$ to 2.7$)$ & +0.8 & $<0.001$ \\
\hline Post-session comfort & 33 & $3.2(2.9$ to 3.5$)$ & & \\
\hline \multicolumn{5}{|l|}{ Intravenous catheter } \\
\hline Previously performed & $33(100 \%)$ & & & \\
\hline Pre-session comfort & 33 & $2.8(2.5$ to 3.1$)$ & +0.8 & $<0.001$ \\
\hline Post-session comfort & 33 & 3.6 (3.3 to 3.8$)$ & & \\
\hline \multicolumn{5}{|l|}{ Central venous catheter } \\
\hline Previously performed & $2(6.7 \%)$ & & & \\
\hline Pre-session comfort & 30 & $1.3(1.1$ to 1.5$)$ & +1.5 & $<0.001$ \\
\hline Post-session comfort & 30 & $2.8(2.5$ to 3.1$)$ & & \\
\hline \multicolumn{5}{|l|}{ Intraosseous access } \\
\hline Previously performed & $2(15.4 \%)$ & & & \\
\hline Pre-session comfort & 13 & $2.2(1.7$ to 2.7$)$ & +1.2 & 0.007 \\
\hline Post-session comfort & 13 & 3.4 (3.0 to 3.7$)$ & & \\
\hline
\end{tabular}

Results of pre- and post-PREP surveys at Dalhousie University, including degree of agreement to the question "Do you understand the daily responsibilities of an anesthesiologist?"; change in participant interest in anesthesiology following PREP; participants' perceptions of the program aspects responsible for their change in anesthesiology interest; and self-reported participant comfort with anesthesiology-related skills following skills sessions (rated on a five-point Likert scale with $1=$ very uncomfortable and 5 = very comfortable)

$\mathrm{CI}=$ confidence interval; PREP $=$ Pre-clerkship Residency Exploration Program

anesthesia rotations should be implemented at Canadian medical schools. Additionally, they found that $50 \%$ of clinical-year students at $\mathrm{U}$ of $\mathrm{A}$ desire a clinical anesthesiology rotation, though one is not offered there. ${ }^{5}$ In lieu of these findings, it may be said that undergraduate medical programs could benefit from the implementation of mandatory anesthesiology rotations or anesthesiology elective programs such as PREP given the increase in understanding and interest in anesthesiology following a two-week elective. Given student interest in anesthesiology and the increase in competition for anesthesiology residency spots, the need for early exposure to the specialty is becoming paramount to help students shape their path in medical school.

Conflicts of interest None declared.

Editorial responsibility This submission was handled by Dr. Gregory L. Bryson, Deputy Editor-in-Chief, Canadian Journal of Anesthesia.

Financial disclosures None. 


\section{References}

1. The Canadian Residency Matching Service. R-1 match interactive data - CaRMS. Available from URL: https://www.carms.ca/datareports/r1-data-reports/r-1-match-interactive-data/ (accessed May 2019).

2. Zeldow PB, Preston $R C$, Daugherty $S R$. The decision to enter a medical specialty: timing and stability. Med Educ 1992; 26: 32732.

3. Haupt TS, Dow T, Smyth M, et al. Medical student exposure to radiation oncology through the Pre-clerkship Residency Exploration Program (PREP): effect on career interest and understanding of radiation oncology. J Cancer Educ 2019; DOI: https://doi.org/10.1007/s13187-019-1477-2.

4. Hamlin $C$, Bhangu $K$, Villafranca A, et al. Participation of Canadian anesthesiology departments in undergraduate medical education. Can J Anesth 2017; 64: 16-28.

5. Henschke SJ, Robertson EM, Murtha L, Tsui BC. Survey of medical students' knowledge and perceptions of anesthesiology at one Canadian university: pre-clerkship and during clinical clerkship, a cohort study. Can J Anesth 2018; 65: 325-6.

Publisher's Note Springer Nature remains neutral with regard to jurisdictional claims in published maps and institutional affiliations. 